\title{
AN ANALYSIS OF STUDENTS' PERCEPTION OF UNIVERSITY SUSTAINABILITY PROGRAMS AND IMAGE
}

\author{
Samuel Adeyanju ${ }^{1}$ \\ ${ }^{1}$ Faculty of Forestry, University of British Columbia, Vancouver, British Columbia, \\ Canada \\ samueloadeyanju@gmail.com
}

Keywords: university, HEI, students, sustainability, UBC, qualitative study, perception

\begin{abstract}
As sustainability gains significance within Higher Education Institutions (HEIs) worldwide, the University of British Columbia (UBC) stands as one of the global champions of sustainability. In 2019, Times Higher Education ranked UBC as number one in the world for taking urgent action to combat climate change and its impacts and ranked one in Canada for making cities inclusive, safe, resilient, and sustainable. Over the years, UBC students have been instrumental to sustainability on the UBC campus by advocating for divestment, climate justice, and other sustainability commitments and projects in the university. Hence, this qualitative study examines students' engagement with or their perception of the university's sustainability programs and image. The study found that students acknowledged and commended the university's sustainability efforts in teaching, research, providing sustainability-related opportunities for students, and in sustainability operations. However, students also addressed hesitation on the part of university administration in championing climate justice and bolder climate action. The conclusion is that continued support and engagement with students are critical for UBC to achieve its climate action plans and sustainability goals in general. The study contributes to the ongoing discourse on the influential role of young people and the youth climate movement in catalyzing ambitious global climate action at all levels.
\end{abstract}

\section{INTRODUCTION}


Sustainability is an economic, social, and ecological concept (Emanuel and Adams, 2011) defined as "meeting the needs of the present generation without compromising the ability of future generations to meet their needs" (Brundtland, 1987). Institutions of higher education worldwide act as role models for their communities, in research, and as critical stakeholders to teach the people that will develop the social, economic, and technological solutions to reverse global warming. These institutions are increasingly showing commitments to sustainability leadership. For example, as of 2011, over 600 universities worldwide have committed themselves towards sustainability by signing both national and international agreements such as the American College and University Presidents Climate Commitment, Bologna Charter, The Halifax Declaration, the Talloires Declaration, and the Copernicus Charter for Sustainable Development" (Emanuel and Adams, 2011, Chiong et al. 2017). In 2019, over 7000 Higher Education Institutions (HEls) from 6 continents declared a 'Climate Emergency' and committed to working with students to tackle the climate crisis [UNEP (United Nations Environment Programme), 2019]. These institutions committed to three broad plans including reaching carbon neutrality, supporting action-oriented climate change research, and comprehensive delivery of environmental and sustainability education (UNEP, 2019). Universities are ideally situated in today's world to actively motivate young minds to engage in sustainability and provide wide-ranging opportunities for students to embrace sustainable lifestyles (Chiong et al. 2017). Sustainability should be promoted as a fundamental principle that not only has practical institutional economic benefits but also encourage a moral lifestyle that is valuable to students' ethical development and contributes to the social welfare of others (Dalton and Crosby, 2012).

\section{The University of British Columbia: a global leader in sustainability}

The University of British Columbia (UBC) is a leader in a global network of postsecondary institutions. UBC has turned its two campuses into a living laboratory of sustainable practice, research, and teaching (Robinson et al., 2013). In 2019-2020, UBC campuses attracted and educated over 66,000 students from 166 countries and employed about 18,000 staff and faculty (UBC, 2021). With over 20 years of achievement in operational and academic sustainability[1], the university exemplifies sustainability in teaching, learning, and research with 21.4 percent of faculty identified as having sustainability research interests and 65 percent of departments offering 
courses with sustainability content (Munro et al., 2016; UBC, 2017). In 2003, UBC completed EcoTREK, the largest energy and water retrofit program on a Canadian university campus. Through EcoTREK, UBC achieved a $27 \%$ reduction of nonrenewable energy consumption in institutional buildings from 2000 levels and a $48 \%$ reduction in potable water use. Subsequently, UBC received a gold rating through STARS (Sustainability Tracking, Assessment and Rating System), a campus sustainability evaluation tool developed by the Association for the Advancement of Sustainability in Higher Education[2] in recognition of its operational and academic track record in August 2011 (Robinson et al., 2013). The university's continued pursuit to integrate operational and academic sustainability across UBC's Vancouver campus led to the creation of the UBC Sustainability Initiative (USI) in January 2010 (Robinson et al., 2013). As of 2015, UBC is the only Canadian institution that is a signatory to the International Sustainable Campus Network Charter (Vaughter et al., 2015). The sustainability image of the university has attracted global recognition including ranking as number one in the world for taking urgent action to combat climate change, according to Times Higher Education (THE) (UBC News, 2019a). Through USI, various sustainability activities have been initiated to engage UBC's students, staff, and faculty. Programs such as paid sustainability internships, on-campus experiential learning projects, Zero-Waste Squad, Sustainability Ambassadors Peer Program, Sustainability Scholars Program, UBC Reads Sustainability are a few among many programs aimed at engaging students in sustainability activities (UBC, 2017).

Research objective: Given the huge commendation, the university's sustainability programs have attracted both locally and internationally, it is important to examine students' experiences and perceptions of the university's sustainability image. Therefore, the overarching aim of the study is to examine the student's engagement with or perception of the university's sustainability programs and image.

\section{METHODS}

For this qualitative study, participant observation, focus group discussions (FGDs) and semi-structured interviews were carried out at the Vancouver campus of the University of British Columbia in March 2018. Using a purposive sampling method, five participants were selected based on their involvement in campus sustainability clubs at 
UBC. All five participants (three females and two males) were student leaders at various campus sustainability clubs namely: UBC sustainability ambassadors program [3] - a university student peer to peer consulting program, the Alma Mata Society (AMS) Sustainability office[4] - UBC Student Society representing undergraduate and graduate students at UBC Vancouver, and Common Energy[5] - the largest student sustainability club at UBC. Five in-depth interviews and one FGD were conducted with the research participants. The interviews and FGDs were recorded and transcribed for thematic coding using NVivo Qualitative data analysis software. Based on the research question, codes were developed by analyzing data for common, repeated and new themes. The themes formed the basis of the results and discussion section.

\section{RESULTS AND DISCUSSION}

This section presents the results and discussion on the perception of students on UBC's sustainability efforts. action.

\subsection{Perception of students of UBC's Sustainability efforts}

\subsubsection{High-quality sustainability teaching, research and extensive sustainability initiatives}

Participants acknowledge that UBC provides considerable opportunities for students to engage in sustainability through teaching, learning, research, operations, campus infrastructure, and community.

"The amount of opportunities that UBC provides in terms of clubs, programs serves as the foundation for student involvement. And I think that leaves with me an impression of a strong sustainability community." (Participant 1 )

This finding aligns with (Emanuel and Adams, 2011, Gardner et al., 2021) on the incorporation of sustainability into teaching, research, and entire campus operations in many USA universities and globally. In addition, participants lauded some specific programs and projects championed by UBC Sustainability Initiative (USI) which encourage students to apply what they learned in class. Topmost on the list is the sustainability ambassadors program which recruits students to champion sustainability amongst the student population on campus while providing incredible learning opportunities and resources for the ambassadors during the process. Similarly, in Polish universities, non-formal (extracurricular) activities were adopted to complement formal educational programs geared towards building sustainability capabilities in students 
(Sady et al. 2019). Furthermore, Given the opportunities available to students to create their own sustainability experience, a group of 12 plus student sustainability clubs on campus formed an alliance called UBC Sustainability Collective to advocate and push for bold climate action both within the Alma Mater Society - AMS (the student society of UBC which represents more than 48,000 students) and UBC. It is this kind of community support that promotes the sustainability movement within the UBC campus: "The opportunities that are provided to the student groups is really important because then it allows us to link our learning outcomes to action in the community and actually make a change in the community." (Participant1) "The sustainability ambassadors program is really a way that the university encourages us to take initiative to make our own sustainability experience. The fact that USI offers that program for students shows they are trying to give resources for students to make change happen." (Participant 3)

\subsubsection{A leader in sustainability operations}

On the sustainability operations of the university, participants commented that the university is making giant strides in this regard.

"It's great that UBC is integrating elements of sustainability into all parts of the campus even just having the waste sorting outstations all across campus that's great or trying to have more vegetarian restaurants opening up."(P.1)

"In terms of sustainability operations or things like energy, waste management, green buildings, I think they've been doing a very good job within their realm of possibilities especially because there's definitely a lot of issues that come up in terms of operations. They are doing a lot more than other places" (P.3,4)

In 2019, UBC ranked number one in the world for taking urgent action to combat climate change and its impacts and ranked one in Canada for making cities inclusive, safe, resilient, and sustainable, according to Times Higher Education (THE) (UBC News, 2019a). As of 2021, UBC is on track to reduce GHG emissions by 67 percent and targeting 100 percent by 2050 (UBC, 2020). The university as a living laboratory concept operationalized on the UBC campuses shows the university's efforts to promote and achieve sustainability (Robinson et al., 2013, UBC, 2017). The living laboratory concept has gained prominence across university campuses globally from United 
Kingdom (Evans et al., 2015) to South Africa (Callaghan and Herselman, 2015), often serving as the main framework for coordinating the universities' sustainability efforts.

\subsubsection{Not enough, we need radical reform}

Globally, many universities are championing sustainability through their research, teaching, and regulation of their institutional footprints (Gardner et al., 2021). However, there has been an increased call to universities to embrace transformative and radical change (Gardner et al., 2021, Green, 2021, Maxwell, 2021).

In the case of UBC, participants suggested that the university should do more in the area of climate justice by pushing for bigger reforms and giving voice to the marginalized people in society.

"The university needs to move the conversation away from operations into more systems thinking, climate justice, climate action. ...thinking about the root cause and the systems that create the problems". (FGD session)

"I think the definition of sustainability that is being used on this campus is actionoriented but it's not justice-oriented. It's usually focused on improving sustainability metrics like waste and emissions. For me, sustainability and climate change are a lot bigger than what USI does. The idea of climate justice is that we need much bigger reforms in our society to address climate change and there are all these power imbalances that exist in society" (P.4)

The above quotes indicate the need for the university do more aligns with a study by Gardner et al., (2021) that suggest the current initiatives promoted by universities still fall short in areas needed to catalyze transformations in our societies and economies. In fact, some authors like Maxwell, have argued that universities have betrayed reason and humanity (Maxwell, 2021) and now represents a part of the problem rather than the solution (Green, 2021). Hence, academia must move beyond publications to public actions through participation in advocacy and activism aimed at effecting urgent and transformational change both in sustainability in other areas such as social justice (Gardner et al., 2021).

\subsubsection{Hesitation before action}

One of the participants has this to say about the response of the university management to the students' push for the university to be more ambitious and take bolder climate 
action than it's currently doing especially in its Next Strategic Plan and Divestment decisions.

My initial thought is that the university management is very receptive until it requires change on their behalf. And then once there is a need for that behavior change there's a lot more resistance but that doesn't necessarily mean that it's not going to happen it's just there's a little bit more negotiation that needs to go into it (P.3) Many years of student-led divestment campaigns and meetings with the University President to discuss their proposal on how the university should handle sustainability issues in its strategic plan have started to yield good results after initial hesitations (Azizi, 2017). For instance, the UBC Board of Governors approved a $\$ 10$ million starting investment into the Sustainable Future Fund (SFF) (Sutcliffe, 2017), and the University funded the establishment of UBC Climate Hub[6] (a student-driven initiative on climate action) (UBC News, 2019b). In addition, after many years of hesitation and delays, the university finally agreed to divest from fossil fuel companies and simultaneously declared a Climate Emergency in December 2019 (UBC News, 2019b).

\section{CONCLUSIONS AND RECOMMENDATIONS}

Indeed, universities can provide one of the best times and places in today's world where youths can be actively motivated to participate in sustainability through the provision of wide-ranging opportunities for students to embrace and practice an environmentally friendly lifestyle (Dalton and Crosby, 2012). This study on UBC students' perception of the sustainability image of the university indicates that students acknowledged and commended the university's sustainability efforts in teaching, research, providing sustainability-related opportunities for students, and in sustainability operations. However, students also addressed hesitation on the part of university administration in championing climate justice and bolder climate action.

The university's declaration of a Climate Emergency in December 2019 is a huge step in the right direction and points to the urgency of climate action. In that line, UBC must implement the report and recommendations of the Climate Emergency Task Force, based on input from about 4,000 students, staff, and faculty across both campuses and beyond (Marcus, 2021; UBC Climate Emergency Task Force, 2021). As a global academic authority and climate leader, UBC can leverage its influence to push for change beyond its institutional boundaries and advocate for just and ambitious climate 
action in the private sector and at all levels of government especially in Canada (Marcus, 2021; UBC Climate Emergency Task Force, 2021). Student groups should continue to engage the university community to push for bolder climate action and hold the university administration accountable for their climate action plans and policies. Students should explore new avenues to engage students outside the sustainability community in their programs, projects and encourage individual commitment to sustainable living. As we have seen in the past three years through the climate strikes and marches across the globe, the youth movement has displayed leadership and are holding private and public sector leaders accountable for their actions and inactions. This study makes the case for university administrations globally to embrace the ideas and solutions presented by their students and see them as important partners in the fight against climate change and in the achievement of the SGDs 2030 agenda.

\section{STUDY LIMITATIONS AND FURTHER WORK}

The author acknowledges that the sample size is quite small with only five interviews and a focus group conducted with interviewees (Similar to Fung and Adams, 2017). Hence, the limited generalizability of the findings of this study to be representative of the student population at UBC. Nevertheless, the interviews were conducted in detail and the result provided sufficient insights needed to address our research questions and draw our conclusions. However, the limitations above offer vital opportunities for future work that can advance our understanding of the sustainability involvements of students in Higher Education Institutions. It is worth highlighting that the results of this study may be different if students from more pro-activism clubs such as UBCC 350 and Environmental Law Group were recruited for this study. This is largely because these student groups are more focused on climate justice and divestment campaigns and could have views different from those expressed by participants in this study. Further work may be carried out to examine if there exist any differences or similarities in the perception of the sustainability image of the university across sustainability student groups that engage in activism and those that engage solely in creating awareness or executing sustainability-related projects. It will also be important to study the experiences of international students (about $30 \%$ of the total student population) who may be new to sustainability especially those from developing countries. 


\section{REFERENCES}

Azizi, J. (2017). Student groups hopeful for progress after sustainability talk with Ono. The Ubyssey August 14, 2017. https://www.ubyssey.ca/news/student-groups-metwith-ono/ [Accessed March 31, 2021]

Brundtland, G. H. (1987). Our Common Future: Report of the World Commission on Environment and Development, New York, NY, United Nations General Assembly. Callaghan, R., and Herselman, M. (2015). Applying a Living Lab methodology to support innovation in education at a university in South Africa. J. Transdisci. Res. Southern Africa, 11, 21-38.

Chiong, K. S., Mohamad, Z. F., and Aziz, A. A. (2017). Factors encouraging sustainability integration into institutions of higher education. Int. J. Environ. Sci.

Technol. 14, 911-922. https://doi.org/10.1007/s13762-016-1164-3

Dalton, J. C., and Crosby, P. C. (2012). Beyond the Glossy Life: Are Colleges and Universities Preparing Students to Build a More Sustainable World? J. Coll. Char. 13, 1-8. https://doi.org/10.1515/jcc-2012-1943

Emanuel, R., and Adams, J. N. (2011). College students' perceptions of campus sustainability. Int. J. Sustain. H. Educ. 12, 79-92.

https://doi.org/10.1108/14676371111098320

Evans, J., Jones, R., Karvonen, A., Millard, L., and Wendler, J. (2015). Living labs and co-production: University campuses as platforms for sustainability science. Curr. Op. Environ. Sustain. 16, 1-6. https://doi.org/10.1016/j.cosust.2015.06.005 Fung, C. Y., and Adams, E. A. (2017). What Motivates Student Environmental Activists on College Campuses? An In-Depth Qualitative Study. Soc. Sci., 6, 134.

https://doi.org/10.3390/socsci6040134

Gardner, C. J., Thierry, A., Rowlandson, W. and Steinberger, J. K. (2021). From Publications to Public Actions: The Role of Universities in Facilitating Academic Advocacy and Activism in the Climate and Ecological Emergency. Front. Sustain. 2:679019 https://doi.org/10.3389/frsus.2021.679019

Green, A. J. (2021). Challenging conventions-a perspective from within and without. Front. Sustain. 2, 22.

Marcus, M. (2021). Letter: It's been a year since UBC declared a climate emergency. The clock is ticking for real action. The Ubyssey. January 12, 2021. 
https://www.ubyssey.ca/opinion/opinion-climate-emergency-action/ [Accessed March 31, 2021]

Maxwell, N. (2021) How Universities Have Betrayed Reason and Humanity—And What's to Be Done About It. Front. Sustain. 2:631631.

https://doi.org/10.3389/frsus.2021.631631

Moore, J. (2005). Policy, priorities and action: A case study of the University of British Columbia's engagement with sustainability. Hig. Educ. Pol. 18, 179-197.

Munro, A., Marcus, J., Dolling, K., Robinson, J., and Wahl, J. (2016). Combining forces: Fostering sustainability collaboration between the city of Vancouver and the University of British Columbia. Int. J. Sustain. H. Educ. 17, 812-826.

https://doi.org/https://doi.org/10.1108//JSHE-04-2015-0082

Robinson, J. B., Berkhout, T., Cayuela, A., and Campbell, A. (2013). "Next Generation Sustainability at The University of British Columbia: The University as Societal Test-Bed for Sustainability," in Regenerative sustainable development of universities and cities: the role of living laboratories, ed. A. Konig (Cheltenham: Edward Elgar), 29-56.

Sady, M., Żak, A., and Rzepka, K. (2019). The role of universities in sustainabilityoriented competencies development: insights from an empirical study on Polish universities. Admin. Sci. 9, 62.

Sutcliffe, S. (2017). Board of Governors approves no fossil fuel Sustainable Future Fund. The Ubyssey. February 20, 2017. https://www.ubyssey.ca/news/board-ofgovernors-approves-no-fossil-fuel-fund/ [Accessed March 31, 2021] UBC. (2017). Annual Sustainability Report 2016-2017. Vancouver. http://report.sustain.ubc.ca/wp-content/uploads/2016/12/Annual-SustainabilityReport.pdf?utm_source=microsite\&utm_term=ASR2016-2017 [Accessed March 31, 2021]

UBC. (2020). Climate Action Plan 2020. Vancouver Campus.

https://planning.ubc.ca/sites/default/files/2019-11/PLAN_UBC_ClimateActionPlan.pdf [Accessed March 31, 2021]

UBC. (2021). UBC overview and facts 2019 - 2020.

https://www.ubc.ca/_assets/pdf/ubc_overview_facts_2019-2020.pdf [Accessed March 31, 2021] 
UBC Climate Emergency Task Force, (2021). UBC climate emergency engagement final recommendations report 2021. http://bm-climate-emergency2020.sites.olt.ubc.ca/files/2021/02/4_2021.02_Climate-Emergency-Engagement.pdf [Accessed March 31, 2021]

UBC News, (2019a). UBC tops global university impact rankings: Times Higher Education. April 3, 2019. https://news.ubc.ca/2019/04/03/ubc-tops-global-universityimpact-rankings-times-higher-education/ [Accessed March 31, 2021] UBC News, (2019b). UBC declares climate emergency and moves forward on two key divestment initiatives. December 5, 2019. https://news.ubc.ca/2019/12/05/ubc-declaresclimate-emergency-and-moves-forward-on-two-key-divestment-initiatives/ [Accessed March 31, 2021] UNEP (United Nations Environment Programme) (2019). Higher and Further Education Institutions Across the Globe Declare Climate Emergency. https://www.unep.org/newsand-stories/press-release/higher-and-further-education-institutions-across-globe-declare [Accessed June 16, 2021]

Vaughter, P., Wright, T., and Herbert, Y. (2015). 50 Shades of Green: An Examination of Sustainability Policy on Canadian Campuses. Can. J. High. Educ. 45, 81-100.

\section{Footnotes}

[1] See Moore (2005) for a detailed analysis of some of UBC's earliest policies on Sustainable Development. See Vaughter et al. (2015) for the first census of the existing environment/sustainability policies and/or plans of 220 Canadian postsecondary institutions.

\section{[2] https://stars.aashe.org/}

[3] https://sustain.ubc.ca/get-involved/sustainability-ambassadors-program

[4] https://www.ams.ubc.ca/how-we-run/sustainability/

[5] https://commonenergyubc.com/

[6] https://ubcclimatehub.ca/about 